\title{
Article
}

\section{Study of Biaxial Mechanical Properties of the Passive Pig Heart: Material Characterisation and Categorisation of Regional Differences}

\author{
Fulufhelo Nemavhola \\ University of South Africa, School of Engineering, Department of Mechanical and Industrial Engineering, \\ Florida, Johannesburg, South Africa 1; masitfj@unisa.ac.za; Tel.: +27-11-471-2354
}

\begin{abstract}
Regional mechanics of the heart is vital in the development of accurate computational models for the pursuit of relevant therapies. Challenges related to heart dysfunctioning are the most important sources of mortality in the world. For example, myocardial infarction (MI) is the foremost killer in sub-Saharan African countries. Mechanical characterisation plays an important role in achieving accurate material behaviour. Material behaviour and constitutive modelling are essential for accurate development of computational models. In most cases previously, the mechanical properties of the heart myocardium were assumed to be homogeneous. The main objective of this paper is to determine the mechanical material properties of healthy porcine myocardium in three regions, namely left ventricle (LV), mid-wall/interventricular septum (MDW) and right ventricle (RV). The biomechanical properties of the pig heart RV, LV and MDW were characterised using biaxial testing. The biaxial tests show the pig heart myocardium behaves non-linearly, heterogeneously and anisotropically. In this study, it was shown that RV, LV and MDW may exhibit slightly different mechanical properties. Data presented here may be helpful in regional tissue mechanics, especially for the understanding of various heart diseases and development of new therapies.
\end{abstract}

Keywords: Mechanical properties; constitutive modelling; cardiac mechanics; anisotropy; biaxial testing

\section{Introduction}

Globally, cardiovascular diseases are posing challenges to public health ${ }^{1}$. In sub-Saharan Africa, these diseases remain problematic since the majority of the population are adversely affected ${ }^{2}$. Challenges related to heart dysfunctioning are the most important sources of mortality in the world. For example, myocardial infarction (MI) is the foremost killer in sub-Saharan African countries ${ }^{3}$. Mechanical characterisation is important in achieving accurate material behaviour. The understanding of biomechanical properties of soft tissue plays a vital role in the development and application of computational models for various diseases ${ }^{4-7}$. It may also lead to accurate comprehension of different disease mechanisms such as MI. The precise understanding of the mechanical behaviour of the heart myocardium in different regions of the heart may assist in the development of accurate constitutive models. This may lead to the development of new therapies and also to the improvement of current therapies. The passive and active properties of heart walls play a pivotal role in understanding its pathophysiological and physiological functions. This could be utilised in the development of accurate and successful surgical procedures as well as in the full development of medical devices and their optimum design, including the design of prostheses ${ }^{8,9}$. For most cardiovascular diseases, especially congenital heart disease, the evolution in the development of accurate and patient-specific computational models could assist in accurate predictive conditions 5,10-13. 
In most cases previously, the mechanical properties of the heart myocardium have been assumed to be homogeneous in the development of computational models to determine the global functioning of the heart 4,6,14,15. It has been clearly demonstrated that the mechanical properties of adult ventricles are different from neonatal porcine ventricles ${ }^{16}$. Following the same logic, the mechanical behaviour of various regions in the pig heart may exhibit different stiffness. Furthermore, in most publications, it has been assumed that material properties of rested hearts in various regions, including LV, MDW and RV have the same mechanical properties. Most authors have considered or studied the mechanical behaviour of the $\mathrm{LV}^{6}$ and RV or both ${ }^{6,16}$. These material properties are then used to develop computational models in understanding various disease mechanisms, including MI. The development of therapies could be achieved by using computational models that have the ability to precisely estimate the regional stresses and strains of tissues ${ }^{17}$. The assumption that heart tissue has the same material properties might not be accurate and if this is the case, the accuracy of computational models could be affected.

Overall, the data for an accurate constitutive model of the MDW remains scarce. The objective of this study was to validate the constitutive model suitable for three heart regions, namely the RV, LV and MDW of the pig heart. This was done systematically by quantifying the material properties of these regions. To achieve this, biaxial tests were performed on the four samples from all three regions of the pig heart. Circumferential and longitudinal loads were performed on the sample. The biaxial testing allowed a study of the effect of applying one load in circumferential direction to the longitudinal direction. To evaluate relevant material parameters for a suitable constitutive model, the average stress-strain curve of the RV, LV and MDW was determined. The comparison of material parameters obtained from two suitable constitutive models is made between the MDW, LV and RV. In addition, these material parameters may be utilised for the development of accurate computational models for studying mechanisms of various cardiovascular diseases.

\section{Materials and methods}

\subsection{Material preparations}

To achieve the objectives of this study, a local abattoir was contacted to supply four fresh mature porcine hearts from pigs weighing about $104 \mathrm{~kg}$. The collected porcine hearts were collected immediately after slaughter and were stored in ice-cooled boxes at $4{ }^{\circ} \mathrm{C}$ during transportation to the biomechanics lab. All the samples were dipped into $0.6 \%$ glutaraldehyde for 20 minutes before testing. To ensure accurate experimentation, the porcine hearts were visually inspected for any structural damage before testing. The FSN coordinate system was virtually inspected by looking at the mean-fibre direction (F), the sheet axis direction (S) and the sheet normal direction (N) ${ }^{18,19}$. The samples were dissected into various regions including LV, RV and septal wall. To conduct the biaxial testing, the ventricles were cut into $18 \times 18 \mathrm{~mm}^{2}$ pieces using a squared-shaped cutting punch. All procedures followed the NIH guidelines for the Guide for the Care and Use of Laboratory Animals.

\subsection{Methods}

Due to the irregular thickness of the myocardium of the pig heart, the thickness was measured by ensuring that at least four measurements were taken at various points of the selected sample. For an accurate reading, the four readings taken were then averaged to obtain the average thickness of the myocardium. The load cell of $23 \mathrm{~N}$ was used in a CellScale biaxial testing machine. A saline solution was used to keep the sample fresh. Also, the saline solution in the bath was allowed to warm up to $37^{\circ} \mathrm{C}$ before any test was conducted. To utilise image tracking, the samples were soaked for 15 minutes in the warm saline bath and then taken out during testing. This was done so as not to compromise the quality of image tracking. The samples were tested using the procedure as described by Ahmad et al. ${ }^{16}$. The image acquisition frequency used in this experiment was $5 \mathrm{~Hz}$. 


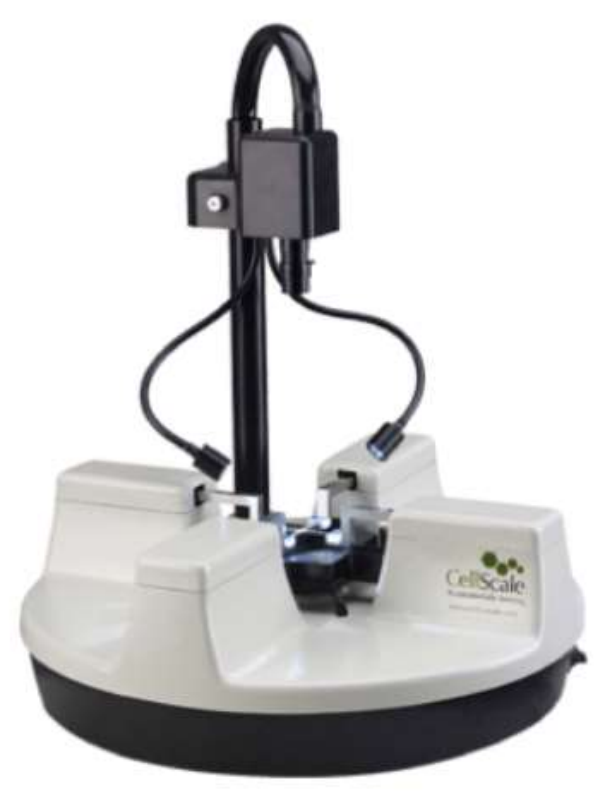

(a)

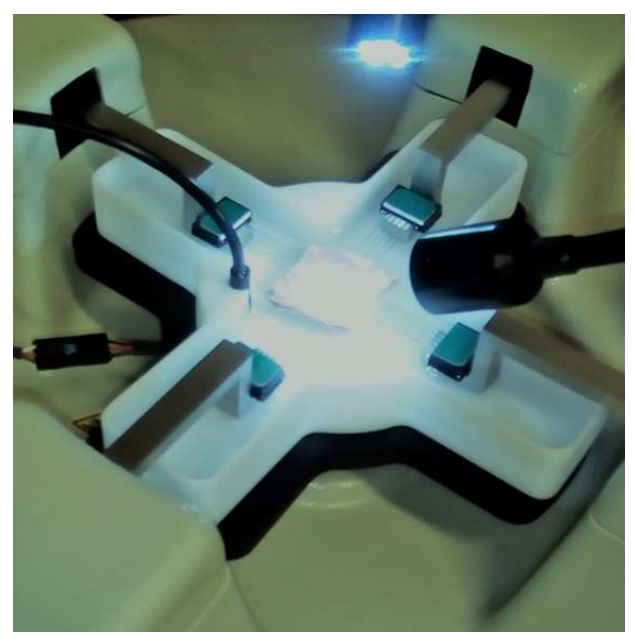

(b)

Figure 1. Biaxial testing equipment (Biotester CellScale $\left.{ }^{\circledR}\right)$ used for testing resting pig heart myocardium.

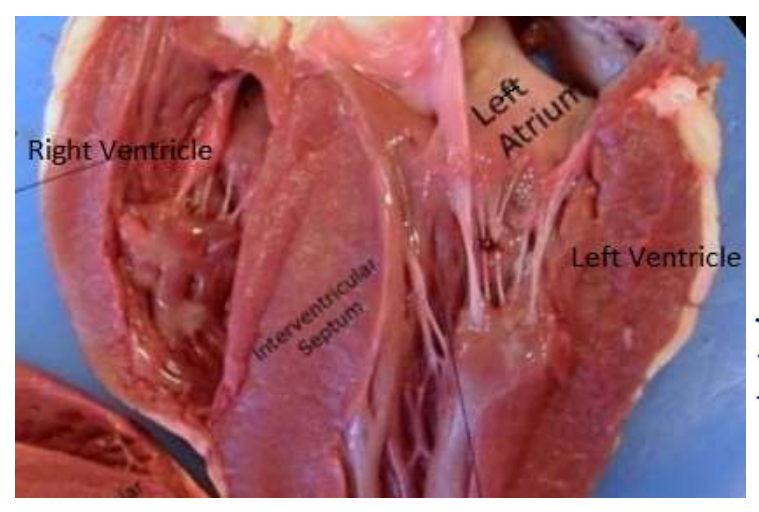

(a)

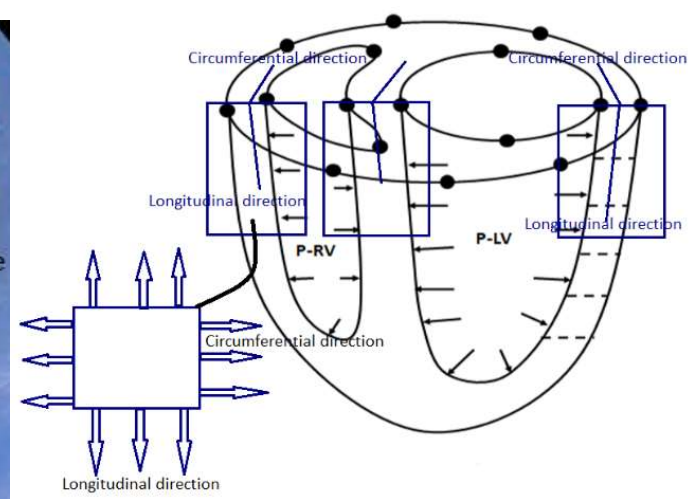

(b)

Figure 2. (a) Pig heart and the three areas (LV, RV and MDW) excised from pig heart myocardium. (b) Schematic diagram of pig heart showing the direction of fibres considered during the sample preparation before biaxial testing in LV, RV and MDW.

\subsection{Biaxial tensile testing equipment}

To capture the biomechanical properties of the passive heart tissue, CellScale biaxial equipment was used ${ }^{20-22}$ (see Figure 1). The frequency of $10 \mathrm{~Hz}$ was used in capturing the force displacement data during biaxial stretching of the myocardium. One sample in each region was cut and the thickness of each sample was measured using a Vernier calliper. All the measurements taken on the sample were recorded to further determine the overall thickness of each sample. $40 \%$ strain was then applied to the myocardium while measuring the force and displacements. The allocated load cell of $23 \mathrm{~N}$ measured the force in each direction independently ${ }^{23}$. To ensure the accuracy of the fibre direction in the heart myocardium, careful inspections were done to ensure that samples were cut accordingly. Additionally, all the RV, LV and MDW regions were cut into equal pieces of $20 \times 20 \mathrm{~mm}^{2}$. 
4 of 18

\subsection{Data analysis}

The mechanical properties of the passive myocardium of porcine hearts in the LV were quantified and compared to those in the RV and MDW regions. Using the Fung and Choi-Vito models, the anisotropic of the materials was calculated using Equation (13). Stress and strain were determined by using Equation (10) and Equation (2), respectively. Equation (3) was then used to determine the cross-sectional area of the tested myocardium in different passive heart regions. In order to satisfy all conditions, Equation (13) and Equation (14) were used 24,25. In this study, the constitutive model fitting was done using the Hyperfit software designed for experimental data fitting of hyperelastic materials ${ }^{26}$. The data analysis on this paper is similar to what was presented previously ${ }^{27}$.

\section{Development of constitutive models}

\subsection{Stress and strain}

To calculate the stress on the tested tissue, the constant cross-sectional area was assumed to be true. The measured force F was used to calculate the stress applied in the cross-sectional area A of the tissue. Therefore, the stress was calculated as follows:

$\sigma_{i}=\frac{F_{i}}{A_{i}}$

The strain $\varepsilon$ was calculated by the following relationships:

$\varepsilon=\frac{\Delta l}{l_{o}}=\frac{l_{i}-l_{o}}{l_{o}}$

$A_{i}=t_{i} l_{i}$

\subsection{Strain field}

Strain is regarded as the general measure of deformation in a material subjected to applied force. The scalar product of the two elemental vectors $d \boldsymbol{X}_{1}$ and $d \boldsymbol{X}_{2}$ after deformation was $d x_{1}$ and $d x_{2}$. The change in scalar product of the two elemental vectors involves a change in length and angle between the two vectors. The material vectors of spatial scalar product $d x_{1} . d x_{2}$ can be found as follows:

$d x_{1} \cdot d x_{2}=d X_{1} \cdot C d X_{2}$

Where $\boldsymbol{C}$ represents the right Cauchy-Green deformation tensor. This tensor is given in terms of the deformation gradient $\mathrm{F}$ as:

$\boldsymbol{C}=\boldsymbol{F}^{T} \boldsymbol{F}$

Alternatively, the left Cauchy-Green or Finger tensor is expressed as follows:

$\boldsymbol{B}=\boldsymbol{F} \boldsymbol{F}^{T}$

The change in scalar product can now be found in terms of the material vectors $d \boldsymbol{X}_{1}$ and $d \boldsymbol{X}_{2}$ and the Lagrangian or Green strain tensor E as:

$\frac{1}{2}\left(d x_{1} \cdot d x_{2}-d \boldsymbol{X}_{1} \cdot d \boldsymbol{X}_{2}\right)=d \boldsymbol{X}_{1} \cdot \boldsymbol{E} d X_{2}$

Where $\boldsymbol{E}$ is defined as the material tensor 
$\boldsymbol{E}=\frac{1}{2}(\boldsymbol{C}-\boldsymbol{I})$

\subsection{Constitutive modelling}

In this study, two constitutive models were considered and utilised in fitting the biaxial experimental data. The first constitutive model is the well-known Fung model ${ }^{28}$. The second constitutive model considered in this study is Choi-Vito, which is similar to the Fung model. The advantage of the Choi-Vito model is that it has three separate exponentials responsible for different fibre directions.

The Fung constitutive model is given by the following strain energy function:

$\varphi=\frac{1}{2} c\left(e^{(Q)}-1\right)$

$\mathrm{Q}$ is a quadratic function of three principal strain components. In this case, $\mathrm{Q}$ represents the special three-dimensional isotropy with regard to the fibre coordinate system. To account for in-plain shear strains ${ }^{29}$, the full expression of the Fung constitutive model was utilised as shown in Equation (10):

$\boldsymbol{Q}=\left[b_{1} E_{11}^{2}+b_{2} E_{22}^{2}+2 b_{3} E_{11} E_{22}+b_{4} E_{12}^{2}+2 b_{5} E_{12} E_{11}+2 b_{6} E_{12} E_{22}\right]$

Where $C, b_{1}, b_{2}, b_{3}, b_{4}, b_{5}$ and $b_{6}$, are absolute constants which are independent of deformation and position in the body. In essence the main function $c$ is to scale stresses. E11 and $\mathrm{E}_{22}$ are the fibre strain and cross-fibre strain, respectively.

$S=\frac{\partial \varphi}{\partial E}=\frac{1}{2} c e^{Q} \frac{\partial \varphi}{\partial E}$

Anisotropy $(A)=\min \left\{\left(\frac{b_{1}+b_{3}}{b_{2}+b_{3}}\right),\left(\frac{b_{2}+b_{3}}{b_{1}+b_{3}}\right)\right\}$

$c>0, b_{1}>\left|b_{3}\right|, b_{2}>\left|b_{3}\right|$ and

$b_{1} b_{2} b_{4}+2 b_{3} b_{6} b_{5}-b_{5}^{2} b_{2}-b_{6}^{1} b_{1}-b_{4} b_{3}^{2}$

The first Piola-Kirchhoff tensor $\boldsymbol{P}$ is an asymmetrical two-point tensor and as such is not completely related to the material configuration. It is possible to contrive a totally material symmetric stress tensor, known as the second Piola-Kirchhoff stress $S$,

$d P=\phi_{*}^{-1}[d p]=F^{-1} d p$

$d P=S d A ; S=J F^{-1} \sigma F^{-T}$

$\delta d=F^{-T} \delta \dot{E} F^{-1}$ and therefor $\boldsymbol{S}=\boldsymbol{F}^{-\mathbf{1}} \boldsymbol{P}$

The Choi-Vito model 30 could be used for modelling soft tissues. In this study, material parameters of the Fung model were compared with those of the Choi-Vito model ${ }^{31}$. The latter has been used for experimental data of various soft tissues including the human coronary artery ${ }^{17}$.

As per the Choi-Vito (1990) model ${ }^{31}$ :

$\varphi=c_{o}\left\{e^{Q_{1}}+e^{Q_{2}}+e^{Q_{3}}-3\right\}$

Where: 
$Q_{1}=c_{1} E_{11}^{2}, Q_{2}=c_{2} E_{22}^{2}, Q_{3}=c_{3} E_{11} E_{22}$

$\mathrm{C}_{0}, \mathrm{C}_{1}, \mathrm{C}_{2}$ and $\mathrm{C}_{4}$ are all material constants of the Choi-Vito model. The Fung model and Choi-Vito model use the material parameters to determine the stiffness and anisotropy of the material.

To ensure the Choi-Vito model accuracy of material parameters, the following conditions must be satisfied and were utilised as follows:

$c_{o}>0, b_{2}>0, b_{1} b_{2}>b_{3}^{2}$

Non-linear stiffness in different directions of the material is determined by the product of $c_{o} \times c_{1}$ and $c_{o} \times c_{2}$. The metric of anisotropy of stiffness is determined by the ratio of $c_{1} / c_{2}$ and interaction between the different axis is indicated by the product of $c_{o} \times c_{3}$.

\section{Results}

The two constitutive models were successfully fit to the experimental data. The Choi-Vito model was found to provide the best fit with the experimental data compared to the Fung model. The thickness of RV, LV and MDW varied considerably. Equation (13) was used to determine the anisotropy of the tissue material of the pig heart in the different regions. The RV, LV and MDW showed an anisotropy of (average \pm standard deviation) of $0.695 \pm 0.110,0.723 \pm 0.212$ and $0.650 \pm$ 0.089 , respectively. A summary of the Fung constitutive analysis in the RV, LV and MDW in the pig heart is given in Tables 1, 2 and 3, respectively. Similarly, a summary of the Choi-Vito model in the $\mathrm{RV}, \mathrm{LV}$ and MDW of the pig heart is given in Tables 5, 6 and 7, respectively. The material parameters of the four pig hearts in the LV, RV and MDW were determined using Equation (4).

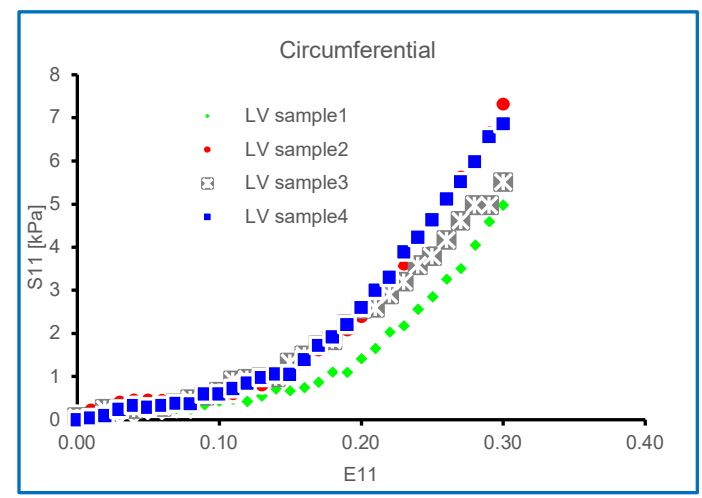

(a)

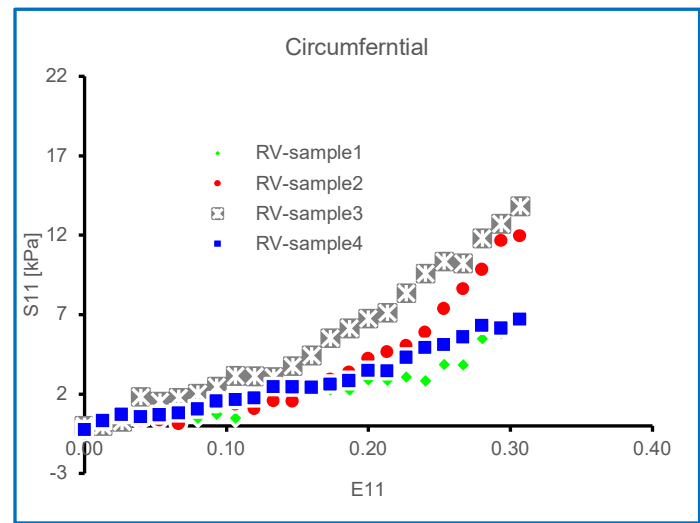

(c)

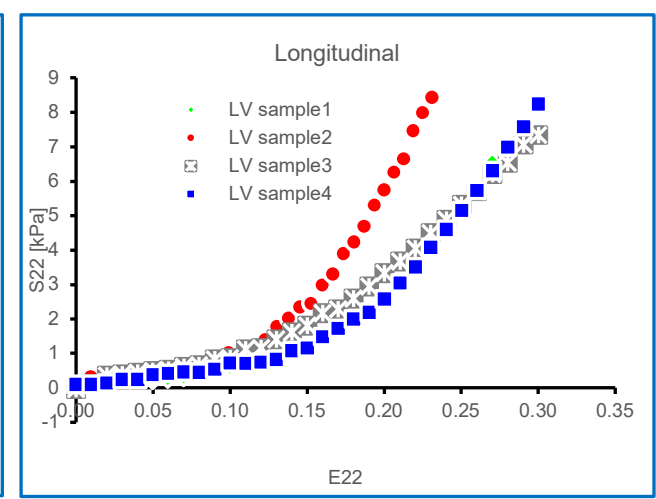

(b)

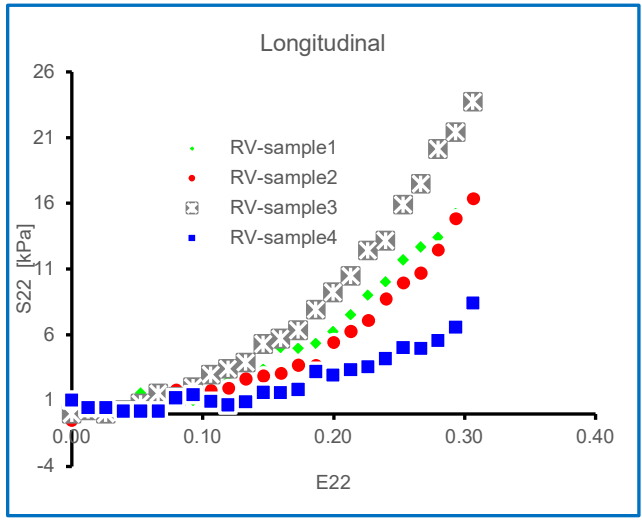

(d) 


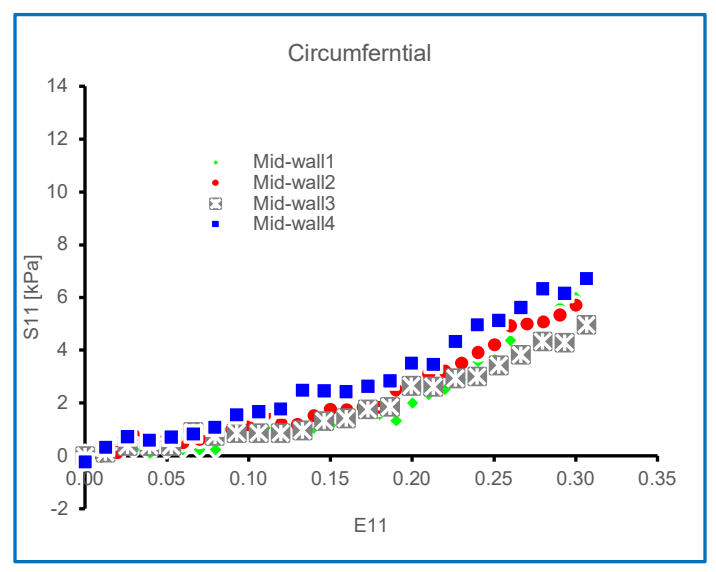

(e)

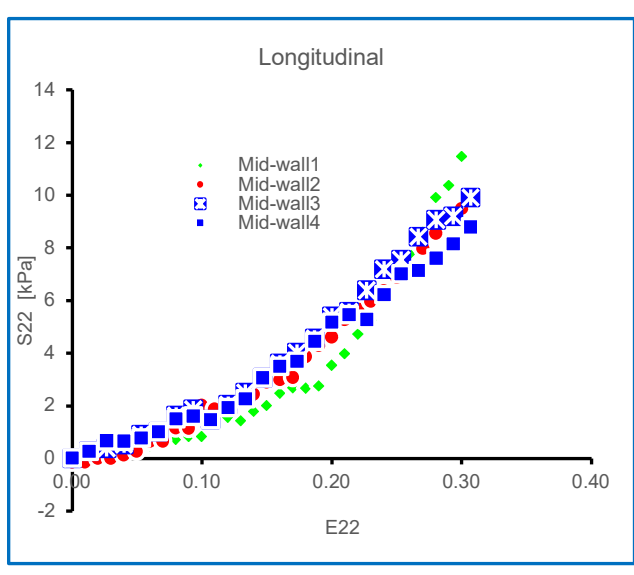

(f)

Figure 3: Experimental data of stress-strain curves was calculated using Equation (3x) and strain was calculated using Equation (X). Stress-strain r LV samples in the (a) sheet direction and (b) normal direction of the cut piece of the pig heart myocardium. Stress-strain curve for four RV samples in the (c) sheet direction and (d) normal direction. Stress-strain curve for four interventricular septum samples in the (e) sheet direction and (f) normal direction of the cut piece of the pig heart myocardium.

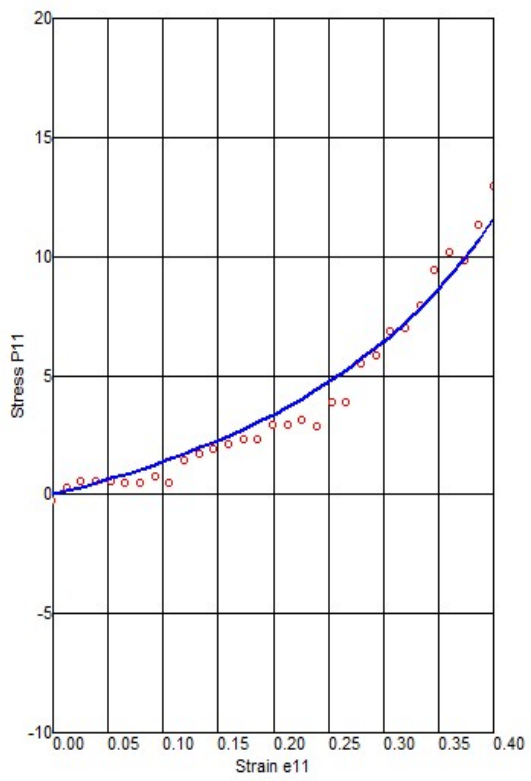

(a)

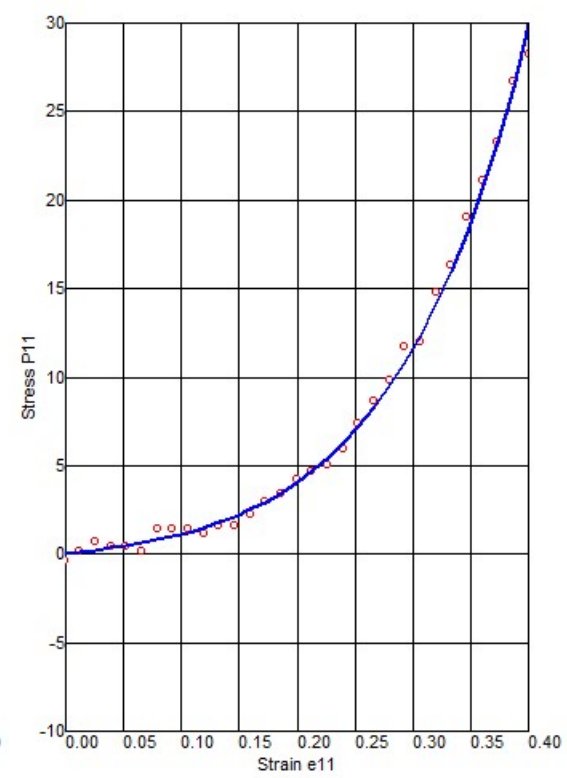

(b) 
8 of 18

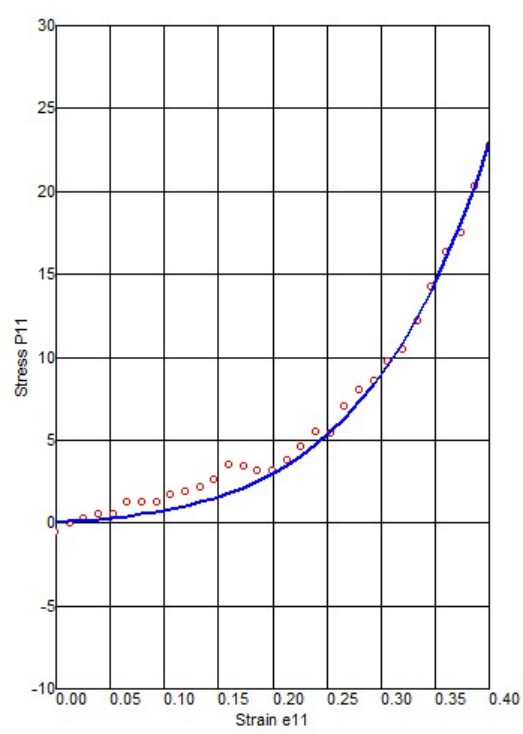

(c)

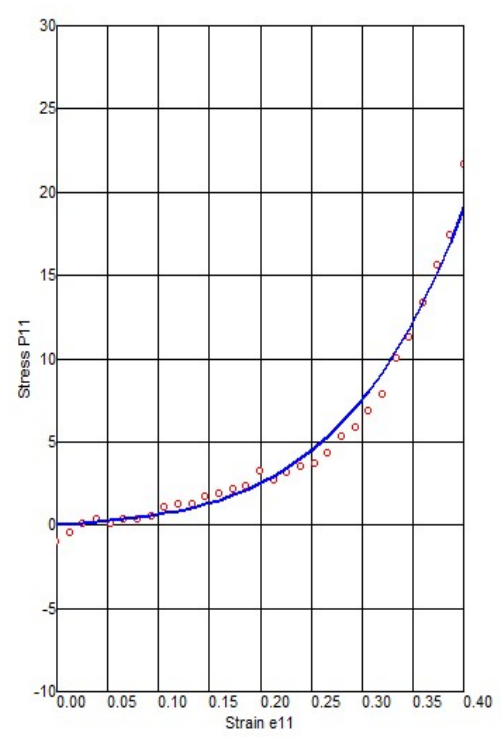

(d)

Figure 4. Curve fitting of experimental data versus the Fung model on the RV sample cut for biaxial testing. (a) RV sample 1, (b) RV sample (2), (c) RV sample 3 and (d) RV sample 4. Unit for Stress P11 is $\mathrm{kPa}$ and Strain E11 is $\mathrm{mm} / \mathrm{mm}$.

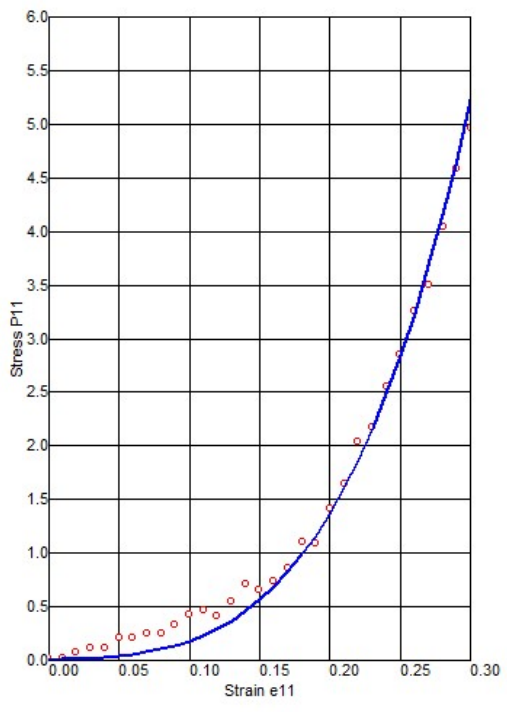

(a)

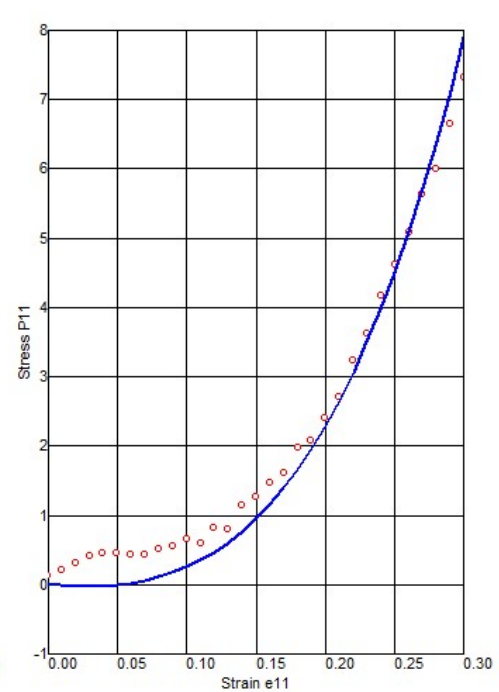

(b) 


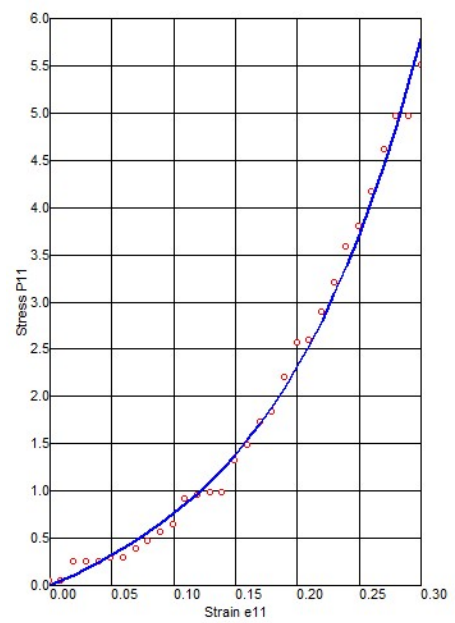

(c)

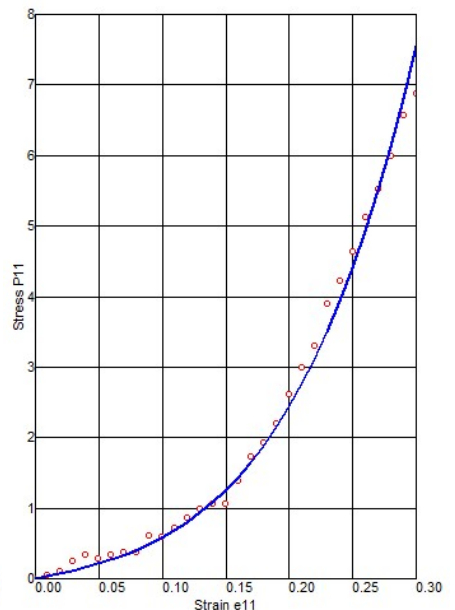

(d)

Figure 5. Curve fitting of experimental data versus the Fung model on the LV sample cut for biaxial Table 1. (b) LV sample (2), (c) LV sample 3 and (d) LV sample 4. Unit for Stress P11 is kPa and Strain $\mathrm{E} 11$ is $\mathrm{mm} / \mathrm{mm}$.

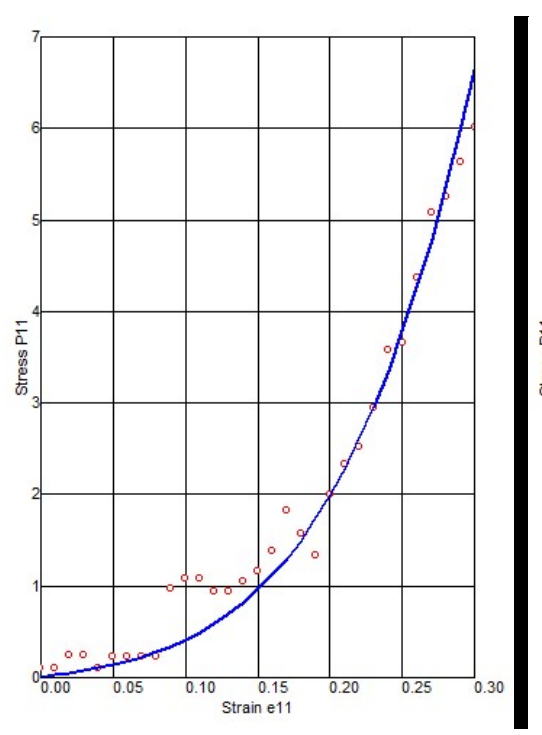

(a)

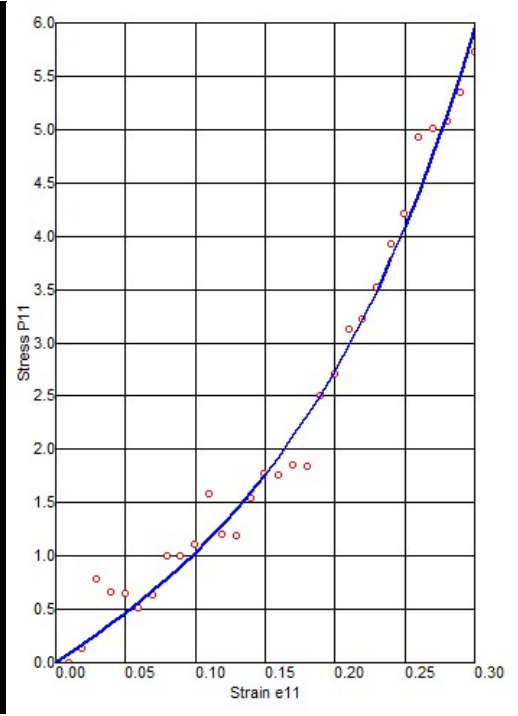

(b) 


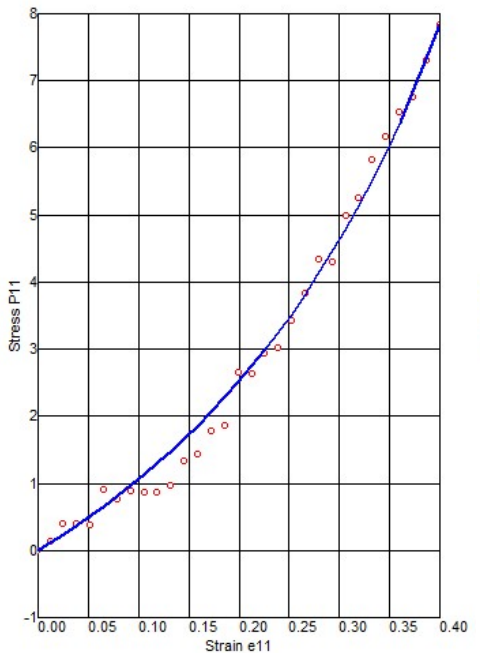

(c)

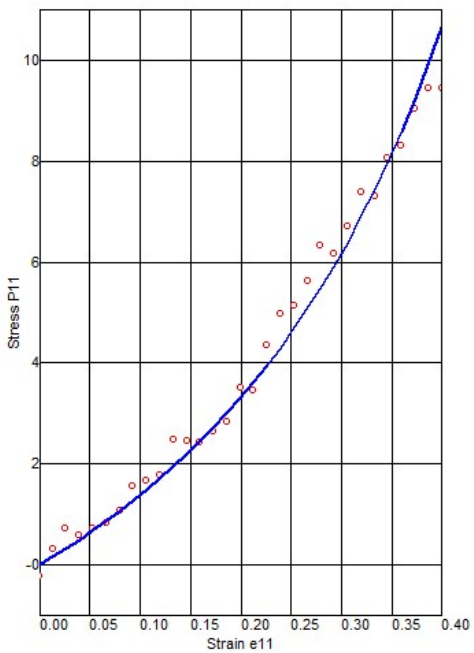

(d)

Figure 6. Curve fitting of experimental data versus the Fung model on the MDW sample cut for biaxial testing. (a) MDW sample 1, (b) MDW sample (2), (c) MDW sample 3 and (d) MDW sample 4. Unit for Stress P11 is $\mathrm{kPa}$ and Strain E11 is $\mathrm{mm} / \mathrm{mm}$.

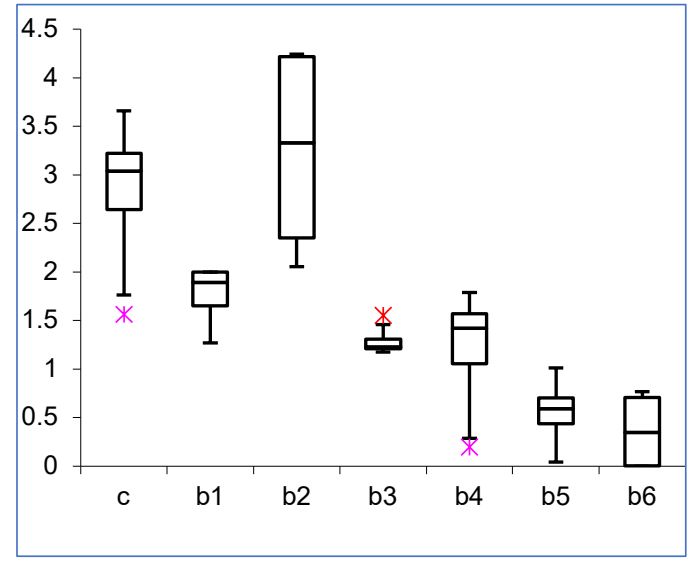

(a)

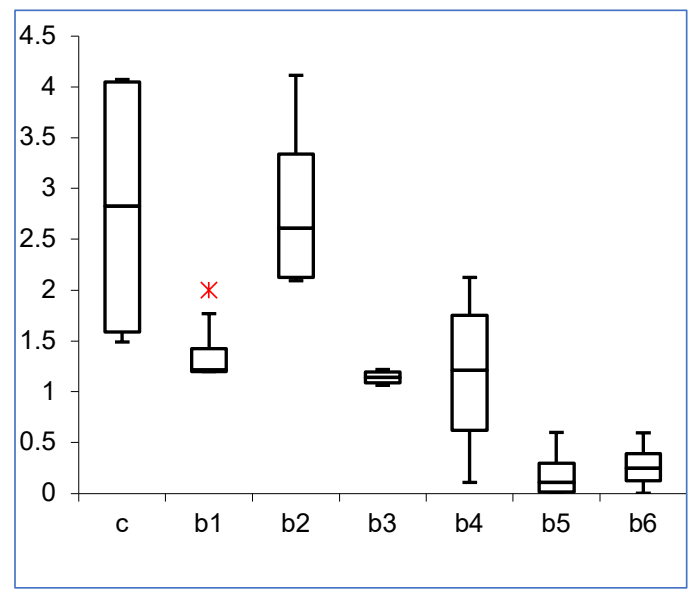

(c)

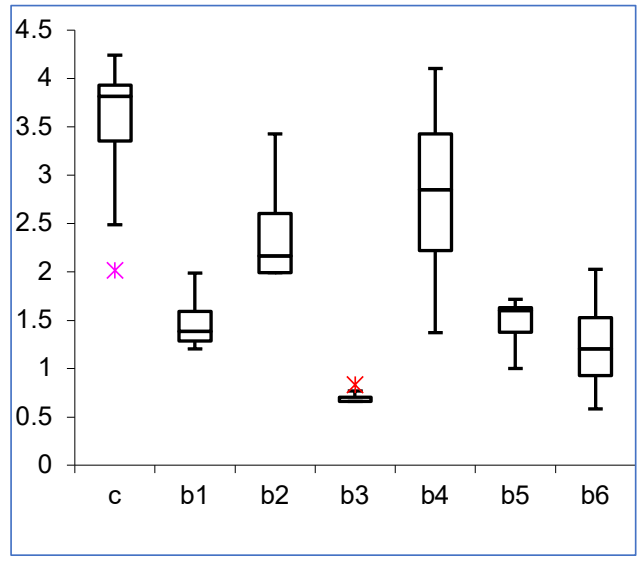

(b)

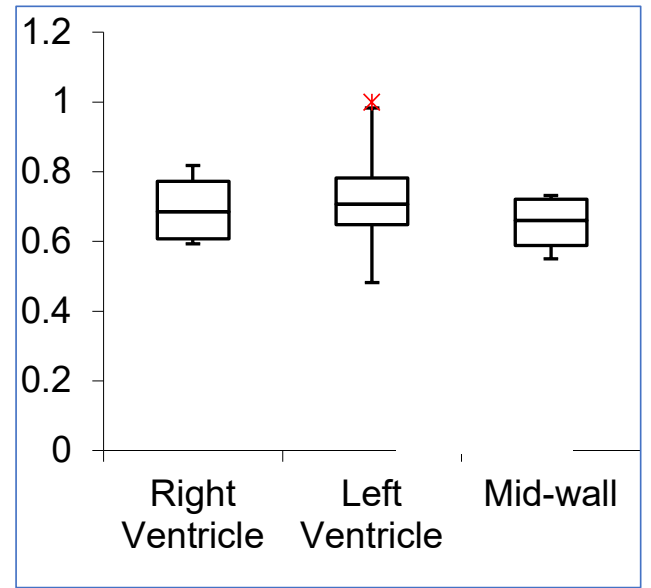

(d) 


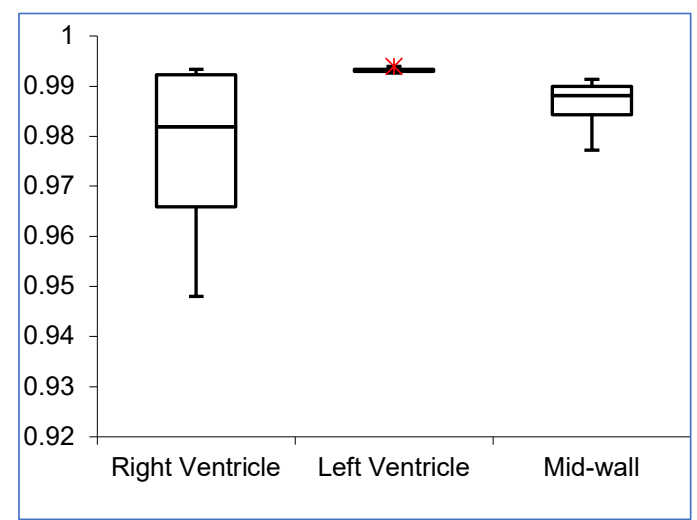

(e)

Figure 7. Box-plot of Fung model mechanical material constitutive parameters $\left(c_{1}, b_{1}, b_{2}, b_{3}, b_{4}\right.$, $b_{5}$ and b6) determined for RV, LV and MDW as shown in Table X. (a) Box plot of RV, (b) box-plot of LV, (c) box plot of MDW, (d) box plot of anisotropy (A) of RV, LV and MDW and (e) box-plot of model for $\left(\mathrm{R}^{2}\right)$ of RV, LV and MDW.

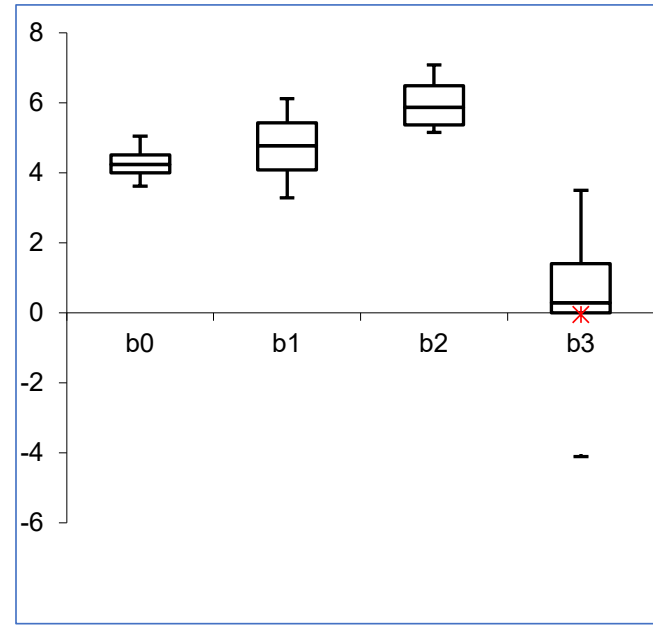

(a)

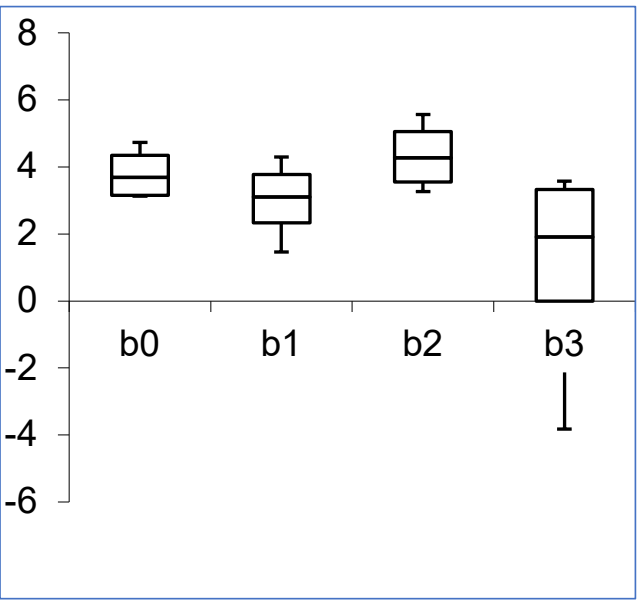

(c)

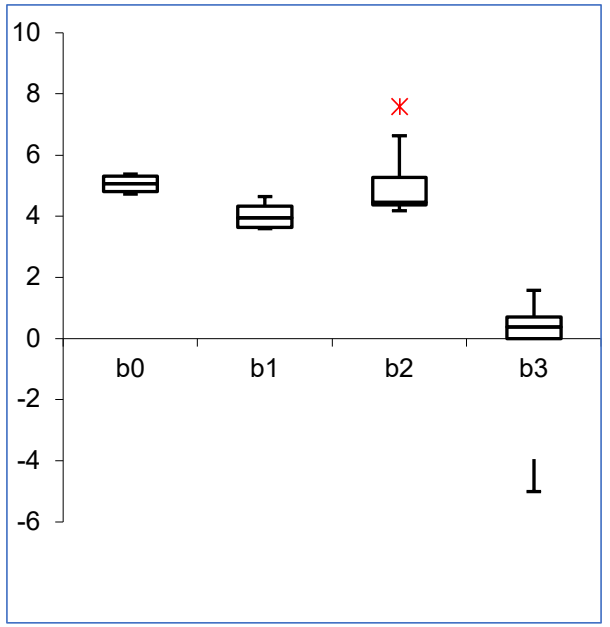

(b)

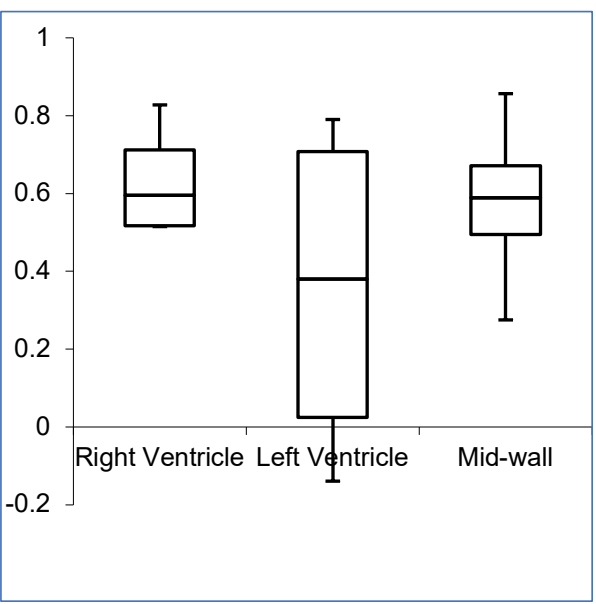

(d) 


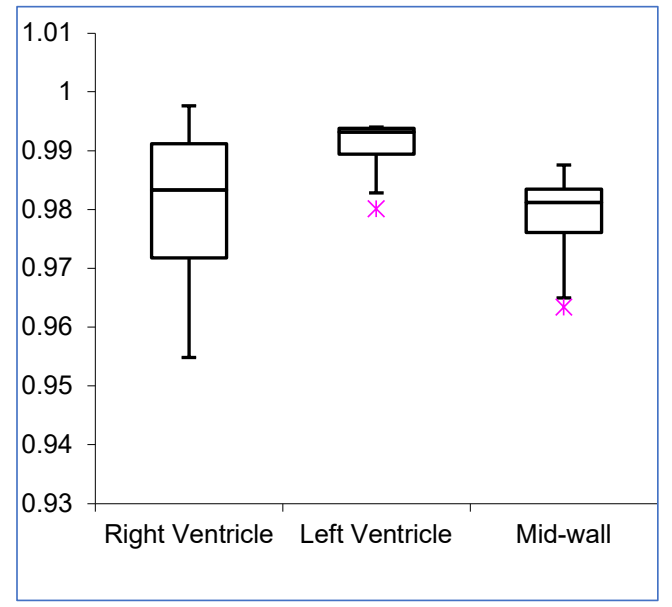

(e)

Figure 8. Box-plot of Choi-Vito model showing the material parameters $\left(\mathrm{c}_{0}, \mathrm{c}_{1}, \mathrm{c}_{2}, \mathrm{c}_{3}\right.$ ) determined for RV, LV and MDW as shown in Table X. (a) Boxplot of RV, (b) box-plot of LV, (c) box-plot of MDW, (d) box plot of anisotropy (A) of RV, LV and MDW and (e) box-plot of model for $\left(\mathrm{R}^{2}\right)$ of RV, LV and MDW.

Figure 3 shows the Experimental data of stress-strain curves was calculated using Equation (3) and strain was calculated using Equation (4). The constitutive material parameters for the Fung and Choi-Vito models are presented in Tables 1-8 for the LV, RV and MDW. The $\mathrm{R}^{2}$ coefficients of each curve for both the Fung and Choi-Vito constitutive models are presented in Tables 1-8. For the Fung model, good fits for average curves of LV, RV and MDW were found to be 0.98, 0.99 and 0.99, respectively. For the Choi-Vito model, good fits for average curves of LV, RV and MDW were found to be $0.98,0.99$ and 0.98 , respectively. For the Choi-Vito model, the anisotropy (A) average of the RV, LV and MDW was found to be $0.633,0.353$ and 0.577 , respectively. For the Fung model, the anisotropy (A) average of the RV, LV and MDW was found to be $0.675,0.723$ and 0.650 , respectively. It was also found that the anisotropy of the RV and LV were similar for the Fung model $(p=0.240)$. Equally, the anisotropy of the RV and MDW were found to be close in the Fung model $(p=0.2259)$. No noteworthy difference in the anisotropy was found between the LV and MDW ( $p=0.238)$. For the Choi-Vito model, the differences in anisotropy between the RV and LV were found to be insignificant $(p=0.165)$. Additionally, no noteworthy differences in anisotropy were found between the RV and MDW ( $p=$ 0.357). The anisotropy of between the RV and MDW using the Choi-Vito model were found to be less significant $(p=0.147)$. Figure 7 shows the box-plot of the Fung model in comparing the material parameters of the RV, LV and MDW regions of the pig heart. The difference in material parameters of the Choi-Vito model in pig heart regions is shown in Figure 8.

Table 1. Material parameters ( $\left.c, b_{1}, b_{2}, b_{3}, b_{4}, b_{5}, b_{6}\right)$ of fitted Fung model Equation (9) on right ventricle $(\mathrm{RV})$ of porcine myocardium including model fit $\left(\mathrm{R}^{2}\right)$ and anisotropy $(\mathrm{A})$ of the same myocardium.

\begin{tabular}{|l|l|l|l|l|}
\hline & Sample 1 (RV) & Sample 2 (RV) & Sample 3 (RV) & Sample 4 (RV) \\
\hline $\mathrm{c}(\mathrm{kPa})$ & 3,661 & 2,998 & 3,078 & 1,565 \\
\hline $\mathrm{b}_{1}$ & 1,999 & 1,781 & 1,270 & 2,000 \\
\hline $\mathrm{b}_{2}$ & 4,244 & 2,452 & 2,054 & 4,207 \\
\hline $\mathrm{b}_{3}$ & 1,551 & 1,228 & 1,176 & 1,22 \\
\hline $\mathrm{b}_{4}$ & 0,199 & 1,791 & 1,495 & 1,342 \\
\hline $\mathrm{b}_{5}$ & 0,598 & $-0,002$ & 0,585 & 1,0106 \\
\hline $\mathrm{b}_{6}$ & 0,689 & 0,767 & 0,0001 & 0,004 \\
\hline
\end{tabular}




\begin{tabular}{|l|l|l|l|l|}
\hline $\begin{array}{l}\text { Anisotropy } \\
(\mathrm{A})\end{array}$ & 0,612597 & 0,817663 & 0,757276 & 0,59333 \\
\hline Fit $\left(\mathrm{R}^{2}\right)$ & 0,948047 & 0,971855 & 0,993354 & 0,991887 \\
\hline
\end{tabular}

Table 2. Material parameters ( $c, b_{1}, b_{2}, b_{3}, b_{4}, b_{5}, b_{6}$ ) of fitted Fung model Equation (9) on left ventricle $(\mathrm{LV})$ of porcine myocardium including model fit $\left(\mathrm{R}^{2}\right)$ and anisotropy $(\mathrm{A})$ of the same myocardium.

\begin{tabular}{|l|r|r|r|r|}
\hline & Sample 1 (LV) & Sample 2 (LV) & Sample 3 (LV) & Sample 4 (LV) \\
\hline $\mathrm{c}(\mathrm{kPa})$ & 2.019 & 3.799 & 4.242 & 3.830 \\
\hline $\mathrm{b}_{1}$ & 1.310 & 1.986 & 1.203 & 1.462 \\
\hline $\mathrm{b}_{2}$ & 3.425 & 1.990 & 1.991 & 2.331 \\
\hline $\mathrm{b}_{3}$ & 0.660 & 0.834 & 0.660 & 0.660 \\
\hline $\mathrm{b}_{4}$ & 3.201 & 4.101 & 1.370 & 2.505 \\
\hline $\mathrm{b}_{5}$ & 1.600 & 1.717 & 0.709 & 1.600 \\
\hline $\mathrm{b}_{6}$ & 1.362 & 2.026 & 0.582 & 1.043 \\
\hline Anisotropy & & & & \\
$(\mathrm{A})$ & 0.482 & 0.999 & 0.703 & 0.710 \\
\hline Fit $\left(\mathrm{R}^{2}\right)$ & 0.993 & 0.994 & 0.993 & 0.993 \\
\hline
\end{tabular}

Table 3. Material parameters ( $c, b_{1}, b_{2}, b_{3}, b_{4}, b_{5}, b_{6}$ ) of fitted Fung model Equation (9) on interventricular septum (MDW) of porcine myocardium including model fit $\left(\mathrm{R}^{2}\right)$ and anisotropy (A) of the same myocardium.

\begin{tabular}{|l|r|r|r|r|}
\hline & \multicolumn{1}{|l|}{$\begin{array}{l}\text { Sample 1 } \\
\text { (Septum wall) }\end{array}$} & $\begin{array}{l}\text { Sample 2 } \\
\text { (Septum wall) }\end{array}$ & $\begin{array}{l}\text { Sample 3 } \\
\text { (Septum wall) }\end{array}$ & $\begin{array}{l}\text { Sample 4 } \\
\text { (Septum wall) }\end{array}$ \\
\hline $\mathrm{c}(\mathrm{kPa})$ & 1.622 & 4.036 & 4.071 & 1.491 \\
\hline $\mathrm{b}_{1}$ & 2.000 & 1.200 & 1.236 & 1.200 \\
\hline $\mathrm{b}_{2}$ & 4.114 & 2.092 & 2.139 & 3.081 \\
\hline $\mathrm{b}_{3}$ & 1.186 & 1.064 & 1.220 & 1.094 \\
\hline $\mathrm{b}_{4}$ & 1.628 & 0.793 & 0.110 & 2.125 \\
\hline $\mathrm{b}_{5}$ & 0.197 & 0.019 & 0,0001 & 0.600 \\
\hline $\mathrm{b}_{6}$ & 0.598 & 0.323 & 0.169 & 0.001 \\
\hline Anisotropy $(\mathrm{A})$ & 0.601 & 0.717 & 0.731 & 0.549 \\
\hline Fit $\left(\mathrm{R}^{2}\right)$ & 0.987 & 0.989 & 0.977 & 0.991 \\
\hline
\end{tabular}


Table 4. Fung model average material parameters $\left(c, b_{1}, b_{2}, b_{3}, b_{4}, b_{5}, b_{6}\right)$ in different regions of the porcine heart. The average curve was determined suing the same method as described in [36].

\begin{tabular}{|l|r|r|r|}
\hline & & & \multicolumn{2}{|c|}{$\begin{array}{l}\text { Mid-wall } \\
\text { Parameters }\end{array}$} & RV region & LV region & region \\
\hline $\mathrm{c}(\mathrm{kPa})$ & 2.826 & 3.473 & 2.805 \\
\hline $\mathrm{b}_{1}$ & 1.763 & 1.490 & 1.409 \\
\hline $\mathrm{b}_{2}$ & 3.239 & 2.434 & 2.857 \\
\hline $\mathrm{b}_{3}$ & 1.294 & 0.704 & 1.141 \\
\hline $\mathrm{b}_{4}$ & 1.207 & 2.794 & 1.164 \\
\hline $\mathrm{b}_{5}$ & 0.548 & 1.407 & 0.204 \\
\hline $\mathrm{b}_{6}$ & 0.365 & 1.253 & 0.273 \\
\hline Anisotropy $(\mathrm{A})$ & 0.695 & 0.723 & 0.650 \\
\hline Fit $\left(\mathrm{R}^{2}\right)$ & 0.976 & 0.993 & 0.986 \\
\hline
\end{tabular}

Table 5. Material parameters ( $\left.\mathrm{C}_{2}, \mathrm{C} 1, \mathrm{C} 2, \mathrm{c} 3\right)$ of fitted Choi-Vito model using Equation (15) on right ventricle (RV) of porcine myocardium including model fit $\left(R^{2}\right)$ and anisotropy $(A)$ of the same myocardium.

\begin{tabular}{|c|c|c|c|c|}
\hline & $\begin{array}{l}\text { Sample } 1 \\
(\mathrm{RV})\end{array}$ & $\begin{array}{l}\text { Sample } 2 \\
(\mathrm{RV})\end{array}$ & Sample 3 (RV) & $\begin{array}{l}\text { Sample4 } \\
\text { (RV) }\end{array}$ \\
\hline $\mathrm{R}^{2}$ & 0.977 & 0.998 & 0.989 & 0.955 \\
\hline $\mathrm{c} 0(\mathrm{kPa})$ & 3.623 & 4.127 & 4.336 & 5.051 \\
\hline $\mathrm{C}_{1}$ & 3.282 & 6.116 & 5.201 & 4.35 \\
\hline $\mathrm{C} 2$ & 6.293 & 7.088 & 5.448 & 5.151 \\
\hline $\mathrm{C} 3$ & -0.049 & -4.104 & -4.018 & -3.501 \\
\hline Anisotropy (A) & 0.518 & 0.674 & 0.827 & 0.514545 \\
\hline
\end{tabular}

Table 6. Material parameters ( $\mathrm{C}_{0}, \mathrm{C}_{1}, \mathrm{C}_{2}, \mathrm{C}_{3}$ ) of fitted Choi-Vito model Equation (15) on mid-wall (MDW) of porcine myocardium including model fit $\left(\mathrm{R}^{2}\right)$ and anisotropy $(\mathrm{A})$ of the same myocardium.

\begin{tabular}{|c|c|c|c|c|}
\hline & $\begin{array}{l}\text { Sample } 1 \\
\text { (Septum } \\
\text { wall) }\end{array}$ & $\begin{array}{l}\text { Sample } 2 \\
\text { (Septum } \\
\text { wall) }\end{array}$ & $\begin{array}{l}\text { Sample } \\
\text { 3(Septum wall) }\end{array}$ & $\begin{array}{l}\text { Sample } \\
4 \\
\text { (Septum } \\
\text { wall) }\end{array}$ \\
\hline Fit $\left(\mathrm{R}^{2}\right)$ & 0.982 & 0.988 & 0.980 & 0.963 \\
\hline $\mathrm{co}(\mathrm{kPa})$ & 4.727 & 4.215 & 3.131 & 3.161 \\
\hline $\mathrm{C}_{1}$ & 4.300 & 3.594 & 1.457 & 2.633 \\
\hline $\mathrm{C} 2$ & 5.565 & 4.892 & 3.652 & 3.261 \\
\hline $\mathrm{C} 3$ & -3.821 & -1.571 & 1.437 & 1.117 \\
\hline Anisotropy (A) & 0.275 & 0.609 & 0.569 & 0.857 \\
\hline
\end{tabular}


Table 7. Material parameters ( $\mathrm{C}_{0}, \mathrm{C}_{1}, \mathrm{C}_{2}, \mathrm{C}_{3}$ ) of fitted Choi-Vito model Equation (15) on left ventricle (LV) of porcine myocardium including model fit (R2) and anisotropy (A) of the same myocardium.

\begin{tabular}{|c|c|c|c|c|}
\hline & $\begin{array}{l}\text { Sample } 1 \\
(\mathrm{LV})\end{array}$ & $\begin{array}{l}\text { Sample } 2 \\
(\mathrm{LV})\end{array}$ & Sample 3 (LV) & $\begin{array}{l}\text { Sample } 4 \\
\text { (LV) }\end{array}$ \\
\hline Fit $\left(R^{2}\right)$ & 0.993 & 0.980 & 0.994 & 0.994 \\
\hline $\mathrm{co}_{0}(\mathrm{kPa})$ & 5.291 & 4.730 & 4.823 & 5.379 \\
\hline $\mathrm{C} 1$ & 3.655 & 4.641 & 3.599 & 4.233 \\
\hline $\mathrm{C}_{2}$ & 4.499 & 7.578 & 4.183 & 4.423 \\
\hline C3 & -3.582 & -5.000 & -2.358 & -3.517 \\
\hline Anisotropy (A) & 0.080 & 0.139 & 0.680 & 0.790 \\
\hline
\end{tabular}

Table 8. Choi-Vito model average material parameters $\left(\mathrm{c}_{0}, \mathrm{C}_{1}, \mathrm{c}_{2}, \mathrm{c}_{3}\right)$ in different regions of the porcine heart. The average curve was determined using the same method as described in [36].

\begin{tabular}{|l|r|r|r|}
\hline Parameters & \multicolumn{1}{|l|}{ RV region } & \multicolumn{1}{|l|}{ LV region } & \multicolumn{1}{l|}{ region } \\
\hline Co $(\mathrm{kPa})$ & 4.284 & 5.056 & 3.809 \\
\hline C1 & 4.737 & 4.032 & 2.996 \\
\hline C2 & 5.995 & 5.171 & 4.343 \\
\hline C3 & -2.918 & -3.614 & -0.710 \\
\hline Anisotropy $(\mathrm{A})$ & 0.633 & 0.353 & 0.577 \\
\hline Fit $\left(\mathrm{R}^{2}\right)$ & 0.980 & 0.990 & 0.978 \\
\hline
\end{tabular}

\section{Discussion and conclusions}

This study shows that the mechanical behaviour of porcine myocardial tissue is non-linear and anisotropic. Most often only the LV is considered 32-34. However, in this study, the overall characteristic of the LV, MDW and RV is consistent with other soft tissues ${ }^{25,35,36}$. Biaxial testing in the LV, MW and RV was conducted. Even though experimental data is available on the LV myocardium of porcine, no biaxial experimental data is available for the RV and MDW. Five fresh porcine hearts were tested using biaxial test equipment. Biaxial deformation was performed on the LV myocardium, RV myocardium and MDW. The biaxial experimental data was fit to the Fung exponential function. Interesting observations were made regarding the different mechanics of these regions of the pig heart.

To the author's knowledge, this study presents an interesting finding. In most cases previous, the material properties of porcine have been assumed to be the same in all regions of the heart. This means that the computational models developed also depend on this assumption. In this experiment, the material properties of the LV, RV and MDW of the porcine heart were found not to be the same and should be treated as such. The important observation is that the stiffness confident $b_{3}$ is zero in all regions. As a result of the myocardial tissue structure, the cardiac tissue has been found to show non-linear material behaviour 16,37. The material behaviour of myocardial tissue in different heart regions may differ based on the variation of the intricate structure.

Mechanical properties of the myocardial tissues play an important role in the development of computational models to study various mechanisms of heart diseases. Inaccuracy in the mechanical properties of the heart region may affect the accuracy of the computational models developed. Computational modelling is increasingly utilised to further understand pathological conditions. Various new interventions and therapies have been developed based on knowledge gained from these computational models. 
Regional differences in material parameters in a passive pig heart were found. This finding is similar to that regarding the small intestine, where it was observed that passive small intestine tissue exhibits material parameter differences based on location ${ }^{38,39}$. Similarly, it was also observed that porcine small bowel mesentery may exhibit different material parameters of the Fung model in different regions ${ }^{40}$.

To model the mechanical response of the passive pig heart tissue in three different regions, the Fung model ${ }^{28}$ and Choi-Vito model ${ }^{30}$ were selected as shown in Figure 2 (a). In Figure 2 (b) the direction of the fibres used during mechanical testing in the passive myocardium is shown. The two constitutive models were also selected based on the accuracy of fit $\left(R^{2}\right)$ as shown in Figures 4,5 and 6. As shown in Tables 3, 4 and 5, the Fung model was able to fit the experimental data as expected. However, the Choi-Vito model (see values of $R^{2}$ in Tables 5, 6 and 7) proved to fit the experimental data well. It was found that there is no major difference of $\mathrm{R}^{2}$ between the fit experimental data using the Fung and Choi-Vito models (see Tables 4 and 8). An average Fung and Choi-Vito model in three different pig heart regions could be utilised for the development of computational models as listed in Tables 4 and 8 . Like various soft tissues 19,24,41, passive myocardium in the three different regions were found to be anisotropic. In this study, the average material parameters in the RV, LV and MDW regions of passive pig heart can be employed in finite element analysis (FEA). FEA may then be utilised to study the mechanisms of MI in different stages by obtaining the average regional stresses and strains of the myocardium.

Acknowledgement: This work was supported by the University of South Africa through the acquisition of biaxial testing (Biotester CellScale) equipment used in conducting this experiment.

Compliance with Ethical Standards: This study was funded by the University of South Africa through CAPEX programme.

Conflict of Interest: The author declares that he has no conflict of interest.

Ethical approval: All applicable international, national, and/or institutional guidelines for the care and use of animals were followed.

\section{References}

1 Roth, G. A. et al. Global, regional, and national burden of cardiovascular diseases for 10 causes, 1990 to 2015. Journal of the American College of Cardiology 70, 1-25 (2017).

2 Boateng, D. et al. Cardiovascular disease risk prediction in sub-Saharan African populationsComparative analysis of risk algorithms in the RODAM study. International journal of cardiology 254, 310-315 (2018).

3 Boateng, D., Agyemang, C., Kengne, A. P., Grobbee, D. E. \& Klipstein-Grobusch, K. Cardiovascular disease risk prediction in low income settings: A call for context specific risk equations. International journal of cardiology 265, 239 (2018).

$4 \quad$ Nemavhola, F. Fibrotic infarction on the LV free wall may alter the mechanics of healthy septal wall during passive filling. Bio-Medical Materials and Engineering 28, 579-599 (2017).

5 Masithulela, F. J. Computational biomechanics in the remodelling rat heart post myocardial infarction, University of Cape Town, (2016).

6 Masithulela, F. Bi-ventricular finite element model of right ventricle overload in the healthy rat heart. Bio-medical materials and engineering 27, 507-525 (2016).

$7 \quad$ Nemavhola, F. Mechanics of the septal wall may be affected by the presence of fibrotic infarct in the free wall at end-systole. International Journal of Medical Engineering and Informatics 11, 205-225 (2019).

8 Martinsson, A. et al. Outcomes associated with dual antiplatelet therapy after myocardial infarction in patients with aortic stenosis. International journal of cardiology 281, 140-145 (2019). 
Stavropoulou, E. A., Dafalias, Y. F. \& Sokolis, D. P. Biomechanical and histological characteristics of passive esophagus: experimental investigation and comparative constitutive modeling. Journal of biomechanics 42, 2654-2663 (2009).

Gallo, D., Montanaro, C. \& Morbiducci, U. Computational modelling in congenital heart disease: Challenges and opportunities. International journal of cardiology 276, 116-117 (2019).

$\mathrm{Yu}, \mathrm{H}$. et al. Patient-specific in vivo right ventricle material parameter estimation for patients with tetralogy of Fallot using MRI-based models with different zero-load diastole and systole morphologies. International journal of cardiology 276, 93-99 (2019).

Nordbø, Ø. et al. A computational pipeline for quantification of mouse myocardial stiffness parameters. Computers in biology and medicine 53, 65-75 (2014).

Masithulela, F. in ASME International Mechanical Engineering Congress and Exposition. 88-97 (American Society of Mechanical Engineers, 2016).

Masithulela, F. J. Computational biomechanics in the remodelling rat heart post myocardial infarction Doctoral thesis, University of Cape Town, (2016).

Masithulela, F. in ASME 2015 International Mechanical Engineering Congress and Exposition. V003T003A005-V003T003A005 (American Society of Mechanical Engineers).

Ahmad, F. et al. Biomechanical properties and microstructure of neonatal porcine ventricles. Journal of the mechanical behavior of biomedical materials 88, 18-28 (2018).

Kural, M. H. et al. Planar biaxial characterization of diseased human coronary and carotid arteries for computational modeling. Journal of biomechanics 45, 790-798 (2012).

Dokos, S., Smaill, B. H., Young, A. A. \& LeGrice, I. J. Shear properties of passive ventricular myocardium. American Journal of Physiology-Heart and Circulatory Physiology 283, H2650-H2659 (2002).

Sommer, G. et al. Biomechanical properties and microstructure of human ventricular myocardium. Acta biomaterialia 24, 172-192 (2015).

Fatemifar, F., Feldman, M. D., Oglesby, M. \& Han, H.-C. Comparison of Biomechanical Properties and Microstructure of Trabeculae Carneae, Papillary Muscles, and Myocardium in the Human Heart. Journal of biomechanical engineering 141, 021007 (2019).

Kramer, K. et al. An Investigation of Layer-Specific Tissue Biomechanics of Porcine Atrioventricular Valve Anterior Leaflets. Available at SSRN 3321895 (2019). Anssari-Benam, A., Tseng, Y.-T., Holzapfel, G. A. \& Bucchi, A. Rate-dependency of the mechanical behaviour of semilunar heart valves under biaxial deformation. Acta biomaterialia (2019).

Nemavhola, F. Biaxial quantification of passive porcine myocardium elastic properties by region. Engineering Solid Mechanics 5, 155-166 (2017).

Bellini, C., Glass, P., Sitti, M. \& Di Martino, E. S. Biaxial mechanical modeling of the small intestine. Journal of the mechanical behavior of biomedical materials 4, 1727-1740 (2011).

Aydin, R. et al. Experimental characterization of the biaxial mechanical properties of porcine gastric tissue. Journal of the mechanical behavior of biomedical materials 74, 499-506 (2017). de Bortoli, D., Wrubleski, E., Marczak, R. J. \& Júnior, J. G. in Proceedings of COBEM.

Ndlovu, Z., Nemavhola, F. \& Desai, D. BIAXIAL MECHANICAL CHARACTERIZATION AND CONSTITUTIVE MODELLING OF SHEEP SCLERA SOFT TISSUE. Russian Journal of Biomechanics/Rossijski Zurnal Biomehaniki 24 (2020).

Fung, Y. What are the residual stresses doing in our blood vessels? Annals of biomedical engineering 19, 237-249 (1991). 
Sacks, M. S. Biaxial mechanical evaluation of planar biological materials. Journal of elasticity and the physical science of solids 61, 199 (2000).

Choi, H. S. \& Vito, R. Two-dimensional stress-strain relationship for canine pericardium. Journal of biomechanical engineering 112, 153-159 (1990).

1

Geest, J. P. V., Sacks, M. S. \& Vorp, D. A. A planar biaxial constitutive relation for the luminal layer of intra-luminal thrombus in abdominal aortic aneurysms. Journal of biomechanics 39, 2347-2354 (2006).

(

Brooks, P. A., Khoo, N. S. \& Hornberger, L. K. Systolic and diastolic function of the fetal single left ventricle. Journal of the American Society of Echocardiography 27, 972-977 (2014).

Khalafvand, S. et al. Assessment of human left ventricle flow using statistical shape modelling and computational fluid dynamics. Journal of biomechanics 74, 116-125 (2018).

Shen, J. J., Xu, F. Y. \& Yang, W. A. Finite element analysis of left ventricle during cardiac cycles in viscoelasticity. Computers in biology and medicine 75, 63-73 (2016).

Cooney, G. M. et al. Uniaxial and biaxial tensile stress-stretch response of human linea alba. Journal of the mechanical behavior of biomedical materials 63, 134-140 (2016).

Duprey, A., Trabelsi, O., Vola, M., Favre, J.-P. \& Avril, S. Biaxial rupture properties of ascending thoracic aortic aneurysms. Acta biomaterialia 42, 273-285 (2016).

Chalon, A. et al. Contribution of computational model for assessment of heart tissue local stress caused by suture in LVAD implantation. Journal of the mechanical behavior of biomedical materials 82, 291-298 (2018). the rat large intestine: regional dependence of material parameters. Physiological measurement 32, 1969 (2011).

Sokolis, D. P. Experimental study and biomechanical characterization for the passive small intestine: Identification of regional differences. Journal of the mechanical behavior of biomedical materials 74, 93-105 (2017).

Khoiy, K. A., Abdulhai, S., Glenn, I. C., Ponsky, T. A. \& Amini, R. Anisotropic and nonlinear biaxial mechanical response of porcine small bowel mesentery. Journal of the mechanical behavior of biomedical materials 78, 154-163 (2018).

Abbasi, M., Barakat, M. S., Vahidkhah, K. \& Azadani, A. N. Characterization of three-dimensional anisotropic heart valve tissue mechanical properties using inverse finite element analysis. Journal of the mechanical behavior of biomedical materials 62, 33-44 (2016). 